\title{
Evaluation of 3 Tagging Methods in Marking Sea Urchin, Paracentrotuslividus, Populations under Both Laboratory and Field Conditions
}

Cipriano $A^{*}$, Burnell G, Culloty S and Long S

Aquaculture and Fisheries Development Centre School of Biological, Earth and Environmental Sciences University College Cork Distillery Fields North Mall Campus Cork, Ireland

\begin{abstract}
The purple sea urchin, "Paracentrotuslividus" is an Atlanto-Mediterranean species that is of commercial interest for its gonads (or roe) in Europe and Pacific/Asian countries. Individual identification of sea urchins is difficult due to the presence of spines and the structure of the skeletal-like test. However, a successful tagging technique is important for monitoring growth rate and survival of marked individuals in the laboratory and in the field. In addition, tagging can denote ownership, help in brood stock management, and allow for the tracking of animals in the market chain and laboratory experiments. In this study, smaller than previously reported passive integrated.

Transponder (PIT) tags and two external methods (fingernail polish and beads glued to the spines) were tested on "P. lividus" individuals to assess tagging capability, survival, and host response (e.g. lysozyme activity, nitric oxide levels, and cell viability). Additionally, PIT tagged individuals were released in an intertidal rock pool and monitored in order to test field application. Of the three different tagging methodologies, PIT tags were found to be the most successful in both studies carried out in the laboratory in regards to survival and tag retention. In the field, PIT tagged individuals were released and recaptured successfully. Furthermore, host response to individual tagging showed that the individuals were challenged by the sampling methodology which caused increased mortality.
\end{abstract}

Keywords: Fisheries; Paracentrotuslividus; Lysozyme; Aquaculture industry

\section{Introduction}

Demand for high quality seafood is increasing; resulting in the rapid growth of the aquaculture industry, which in turn reduces pressure on capture fisheries. Maximising the potential of the aquaculture industry though, requires innovation to refine existing techniques and apply new technologies [1]. Individual identification in holding conditions is important to monitor growth, behavior, genetics, and population dynamics [2]. The mechanism used to identify individuals must be easily distinguishable, be retained for long periods of time, and have minimal impact on

Growth and behavior if it is to have practical applications $[3,4]$. Individual identification also has further applications in brood stock management, denoting ownership, tracking animals in the market chain, and ecological studies [5] by serving as a marker within the population. However, many commonly farmed aquatic organisms, such as shrimp, sea urchins, and other marine invertebrates, have proven difficult to tag despite recent advances in tagging technology [5-7].

The purple sea urchin, Paracentrotuslividus, is an AtlantoMediterranean species that is of commercial interest for its gonads (or roe) in Europe and Pacific/Asian countries [8,9]. This commercial demand has placed pressure on wild sea urchin populations worldwide and has led to an increased need for aquaculture and hatcheries. In 2010, marine aquaculture produced an estimated 384,300 tons of echinoderms for consumption [10,11] necessitating the establishment of more hatcheries. Individual tagging or identification of sea urchins is difficult due to the presence of spines and the structure of the skeletallike test. Previous studies have focused on external markings to the spines and test [12-14], drilling holes in the test [15-18], fingernail polish plus dental adhesive [14] internal markings, such as tetracycline injections [19-22] and passive integrated transponders (PITs) [6,23-
26]. However, these techniques are often invasive and result in altered behavior and high mortality rates $[27,28]$.

The invasiveness of the tags challenges the individual and could lead to a compromised immune system and possible mortality. Factors affecting the immune system include diseases, condition, and diet [29]. Any factor that challenges an individual can elicit a host response. A tag, whether attached to the spine or test, or inserted into the coelomic cavity, may be treated by the sea urchins immune system as potential invaders. The sea urchins immune system is defined by its immune effectors 35 which have the capacity to respond to injuries, host invasion, and cytotoxic agents [29]. Using immune parameters, there are two means of evaluating host response: 1 ) humoral components such as nitric oxide and lysozyme activity assays and 2) cellular components such cell differentiation counts and cell viability assay. The humoral responses use antimicrobial compounds as a first response to invaders. Nitric oxide, a nitrogen radical produced from L-arginine during phagocytosis, serves as a mechanism of fighting off invasive pathogens [30]. Additionally, lysozyme levels demonstrate defense capabilities through the enzymatic break down of pathogenic cell membranes [31]. Cellular responses directly involve coelomocytes, circulating immune

${ }^{*}$ Corresponding author: Ashlie Cipriano, Aquaculture \& Fisheries Development Centre School of Biological, Earth, \& Environmental Sciences University College Cork Distillery Fields North Mall Campus Cork, Ireland, Tel: +353 (0)85 1643054; E-mail: acipriano@ucc.ie

Received August 08, 2014; Accepted September 27, 2014; Published October 01,2014

Citation: Cipriano A, Burnell G, Culloty S, Long S (2014) Evaluation of 3 Tagging Methods in Marking Sea Urchin, Paracentrotuslividus, Populations under Both Laboratory and Field Conditions. J Aquac Res Development 5: 276 doi:10.4172/2155-9546.1000276

Copyright: ( $) 2014$ Cipriano A, et al. This is an open-access article distributed under the terms of the Creative Commons Attribution License, which permits unrestricted use, distribution, and reproduction in any medium, provided the original author and source are credited. 
cells, Located within the coelomic cavity. Therefore, cell viability and immune cell differentiation are important immune parameters which allow insight into the effects of tagging on P. lividus.

In this study, two laboratory trials looked at internal implanted passive integrated transponder (PIT) tags and two external methods (fingernail polish and beads glued to the spines) when tested on $P$. lividus individuals over a two or four month time period (February-May 2013) in order to assess individual tagging viability and host response. Additionally, PIT tagged individuals were released and detected in the field in West Cork, Ireland using a portable universal microchip reader (RealTrace ${ }^{\circledast}$ R100) in a water proof scuba bag. The overall aim of the study was to identify a tag that was the most suitable for identifying an individual based on (a) tag retention, (b) host response to tags, and (c) survival of P.lividus in the laboratory and in the field.

\section{Materials and Methods}

In this study, three trials were conducted on sea urchins. The first trial (Trial 1) looked at tag retention and survival for 8 weeks in the laboratory. The second trial (Trial 2) looked at tag retention and host response for 4 weeks in the laboratory. The final trial (Trial 3) assessed PIT tag viability in the field.

All P. lividus individuals were sourced from Dunmannus 68 Sea foods sea urchin hatchery in West Cork, Ireland. Both laboratory trials were carried out at ambient temperature $\left(14.0 \pm 1.0^{\circ} \mathrm{C}\right.$; maintained with PSA Aquaclim 10 reversible heatpump/chiller) with continuous water circulation ( $1000 \mathrm{~L}$ sump filled with fresh sea water every 3 days) in four $400 \mathrm{~L}$ black plastic circular tanks. $\mathrm{pH}$ and oxygen saturation (DO) was monitored throughout the experiment to ensure water quality (pH: $8.0 \pm 0.05$ and DO: $8.0 \mathrm{mg} / \mathrm{L} \pm 0.4 \mathrm{mg} / \mathrm{L}$ ). Each tank (both trials) contained 4-5 plastic mesh baskets which each held $10 \mathrm{P}$. lividus individuals and underwent a different tag treatment. In order to acclimate the sea urchins, they were held for 7 days prior to trial commencement. No sea urchin mortalities were recorded during the acclimation period. Animals were fed ablibitum with Laminariasp.

\section{Trial 1: Assessment of different tag options in sea urchins}

General set-up: In each of the tanks, 1 basket held controls, 1 held sea urchins tagged with fingernail polish ( $40 \pm 5 \mathrm{~mm}$ individuals), 1 basket held specimens tagged with beads ( $40 \pm 5 \mathrm{~mm}$ individuals), and 2 baskets each held a different specimen size class $(20 \pm 5 \mathrm{~mm}$ or $40 \pm 5$ $\mathrm{mm}$ individuals) tagged with PIT tags. The control consisted of 10 untagged sea urchins $(40 \pm 5 \mathrm{~mm})$.

External tagging: Two external tags were used (Figure 1b-1c). The first tag type was fingernail polish (Boot's Natural Collection ${ }^{\circ}$ ) applied to the top of an individual sea urchin's spines (approx. 20 spines) after drying spines with cotton. The second tag type was $2 \mathrm{~mm}$ craft beads glued to 5 spines per sea urchin with a BISON non-toxic, non-drip formula super glue gel.

Internal tagging: $1.4 \mathrm{~mm} \times 8 \mathrm{~mm}$ PIT tags (Trovan ${ }^{\circledR}$ ) (Chips4Fish, Zoo Chip, UK) programmed with a unique 12-digit identification number [32] were inserted through the peristome membrane via syringe application [33] (Figure 1a).

Monitoring: Animals were monitored daily for 8 weeks (119 days). External tags (fingernail polish and beads) on each individual sea urchin were counted. Internal tags (PIT Tags) were scanned using a portable universal microchip reader (RealTrace ${ }^{\bullet}$ RT100). Any Dead Sea urchins or sea urchins that had lost their tags (expelled PIT tag or
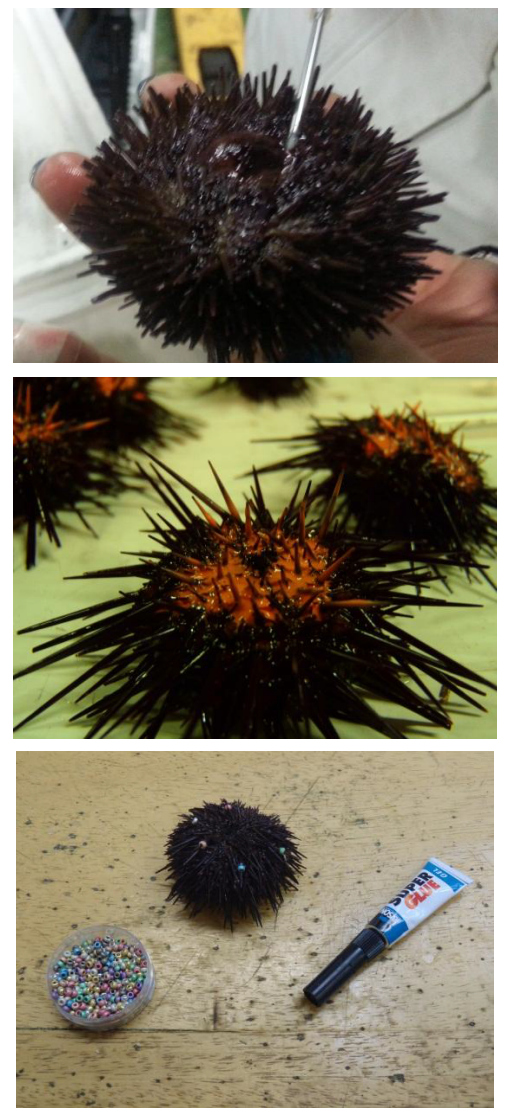

Figure 1: Physical representation of different tagging methodologies.

lost all beads/fingernail polish) were removed from the experimental system.

Trial 2: Host response from tagging of sea urchins in the laboratory

Tagging: Please refer to Trial 1 for general set-up, tagging, and monitoring with the exception that only smaller individuals $(20 \mathrm{~mm} \pm$ $5 \mathrm{~mm}$ ) were used for this trial.

\section{Host response measurements:}

Coelomic fluid collection: Due to the small size of each individual urchin $(20 \pm 5 \mathrm{~mm})$, samples were pooled from the 10 individuals per treatment per tank. An initial baseline sample was taken from 10 individuals prior to tagging. Sampling took place at $2 \mathrm{hrs}$ (T2), $24 \mathrm{hrs}$ (T48), $48 \mathrm{hrs}$ (T48), and then occurred once a week for 4 weeks after tagging to allow for coelomic fluid levels to return to normal and for animals to de-stress between sampling episodes. Each week, $30 \mu \mathrm{l}$ of coelomic fluid was taken from each individual and placed into a 2 $\mathrm{ml}$ eppendorf tube for pooling. Host response was monitored using lysozyme activity, nitric oxide measurements, and cell viability assays. In total, 40 individuals were analyzed per treatment.

Lysozyme activity assay: $200 \mu \mathrm{l}$ of coelomic fluid, pooled from 10 sea urchins per treatment was immediately placed in a $2 \mathrm{ml}$ eppendorf and placed on ice to prevent degradation of the samples. The samples were centrifuged at $3,000 \mathrm{rpm}$ for $10 \mathrm{~min}$ to separate the cells from the serum. The supernatant was removed without disturbing the pellet formed at the bottom of the tube, placed into a clean $2 \mathrm{ml}$ eppendorf 
and stored at $-20^{\circ} \mathrm{C}$ until analysis. The corresponding Pellet was also frozen at $-20^{\circ} \mathrm{C}$. The lysozyme activity assay was carried out as described by Cronin et al. [31], according to Caraballal et al. [34], a modification of Shugar [35]. Lysozyme activity was measured using a 96 well plate reader at a wavelength $(\lambda)$ of $450 \mathrm{~nm}$ which calculated the mean decrease in absorbance at T0, $1 \mathrm{~min}, 2 \mathrm{~min}, 3 \mathrm{~min}$ and 4 min. Duplicate lysozyme standard solutions $(30 \mu \mathrm{l})$ made from hen egg white lysozyme (SIGMA) were serially diluted, were included on each plate and consisted of seven concentrations $5.0 \mu \mathrm{g} / \mathrm{ml}, 2.5 \mu \mathrm{g} / \mathrm{ml}$, $1.25 \mu \mathrm{g} / \mathrm{ml}, 0.625 \mu \mathrm{g} / \mathrm{ml}, 0.3125 \mu \mathrm{g} / \mathrm{ml}$ etc. A corresponding number of blank wells, consisting of $200 \mu \mathrm{l}$ phosphate buffer (0.1M; pH 7.5), were included on each plate. $30 \mu$ of the supernatant of each sea urchin sample (in triplicate) was added to the wells of each plate. $170 \mu \mathrm{l}$ of $M$. lysodeikticussuspension ( $\mathrm{pH}$ 6.4) was added to the wells containing the standard solutions and the sample solutions on each plate to make up to a total volume of $200 \mu \mathrm{l}$ per well.

Nitric Oxide production, Griess reaction: $100 \mu \mathrm{l}$ of coelomic fluid, pooled from 10 sea urchins per treatment, was incubated in a 96 well-plate for $30 \mathrm{~min}$ at room temperature (in triplicate). The same volume of filtered sea water (FSW) was added to the controls and left to incubate for 2 hours. $50 \mu \mathrm{l}$ of supernatant was removed and transferred to a new plate. $50 \mu \mathrm{l}$ of each of the Sodium Nitrite standards: $0.1,0.5$, $1,5,10,50,100 \mu \mathrm{M}$, was added to new wells. $100 \mu$ of Solution A ( $1 \%$ sulphanil amide in $2.5 \%$ phosphoric acid) then $100 \mu$ of Solution B ( $0.1 \%$ N157 naphthyl-ethylenediamine in $2.5 \%$ phosphoric acid) was then added to all wells (samples, standards and blank) and incubated for $5 \mathrm{~min}$ at room temperature. The 96 well plates were placed in a spectrophotometer reader (Elx808 Ultra Microplate Reader, BIO-TEK instruments, INC.) and read at $540 \mathrm{~nm}$.

Cell viability: $100 \mu \mathrm{l}$ of coelomic fluid, pooled from 10 sea urchins per treatment, was incubated in a 96 well-plate for $30 \mathrm{~min}$ at room temperature (in triplicate). The supernatant was removed by overturning the plate. $100 \mu$ l of working neutral red solution (1/50 of stock solution: $0.02 \mathrm{~g}$ in $5 \mathrm{ml}$ of filtered sea water (FSW), filter and maintain in dark) was added to each well and incubated for 2 hours. The supernant was discarded by overturning. Samples were washed with FSW and discarded again. $100 \mu \mathrm{l}$ Lysis169 Solution (1\% Acetic acid and $50 \%$ Ethanol in distilled $\mathrm{H}_{2} \mathrm{O}$ ) was then added to each well. The 96 well plates were placed in a spectrophotometer reader $(540 \mathrm{~nm})$ after being shaken for $1 \mathrm{~min}$.

\section{Trial 3: Individual tagging of sea urchins in the field}

The remaining 44 PIT tagged sea urchins from Trial 1 and 2 (sizes ranging from $20 \pm 5 \mathrm{~mm}$ to $40 \pm 5 \mathrm{~mm}$ ) were ranched in shallow rocky tide pools near the Dunmannus Sea foods sea urchin hatchery in West Cork, Ireland from August to October 2013 for a total of 6 weeks. The urchins were simply released into the rock pool and monitored fortnightly at spring tides using a portable universal microchip reader (Real Trace ${ }^{\oplus}$ R100).

\section{Data analysis}

For both laboratory experiments (Trial 1 and 2), a chi-squared $\left(\chi^{2}\right)$ 183 test was used to indicate the significance of a particular chosen tag type on sea urchin mortality. In Trial 2, post hoc analyses were conducted given the statistically significant ANOVA $(p<0.05)$ for the cell viability and nitric oxide assay results on day 14 (last day where all treatments were still measured). Specifically, Tukey HSD tests were conducted on all possible pair wise contrasts. For the lysozyme activity assay results, individual Kruskal Wallis tests were used to test for significance on day 14 due to the missing data from later sampling points (Table 1).

\section{Results}

\section{Trial 1: Assessment of different tag options in sea urchins}

The controls (urchin size: $40 \mathrm{~mm} \pm 5 \mathrm{~mm}$ ) had a $25 \%$ mortality rate over the four month study period. Within $24 \mathrm{hrs}$, the individuals with fingernail polish painted on their spines (urchin size: $40 \mathrm{~mm} \pm 5 \mathrm{~mm}$ ) started to lift the entire epidermal layer off their tests and drop their spines. By day 29, 100\% mortality was observed in this group. Although the bead methodology had $100 \%$ survival, it was only successful in the short-term as sea urchins survived with the beads up to 29 days before all the beads fell off or the sea urchins dropped the spines holding the beads. Lastly, two size classes of sea urchins contained the PIT tags; small $(20 \pm 5 \mathrm{~mm})$ and large $(40 \pm 5 \mathrm{~mm})$. The large sea 203 urchins showed a $52.5 \%$ mortality rate and the small urchins had a $22.5 \%$ mortality rate over the 8 week study period. All PIT tags remained operational throughout the experiment. A chi-square test indicated that the Choice of a particular tag type was associated with the survival of the sea urchin $(\chi 2206 ; \mathrm{p}<6 \times 10-5207)$.

\section{Trial 2: Host response from tagging of sea urchins in the laboratory}

For Trial 2, only $20 \mathrm{~mm}( \pm 5 \mathrm{~mm})$ individuals were used. The controls showed a $20 \%$ mortality rate. Within the first week, the individuals with fingernail polish started to lift the entire epidermal layer off their tests and dropped their spines with $90 \%$ mortality. By day $21,100 \%$ mortality was observed. As in Trial 1, the bead methodology was more successful, but still observed a $90 \%$ loss of tags by the end of the 28 day experiment. Lastly, urchins that

Contained the PIT tags had $60 \%$ mortality. The individuals that retained their tags survived and were healthy until the end of the experiment. A chi-square test indicated that there was a significant difference between the tag retention by the sea urchins based on the tagging option employed $\left(\chi^{2} ; \mathrm{p}<5.2 \times 10-3219\right)$. Cell viability, nitric oxide levels, and lysozyme activity were measured to evaluate host response to tagging. The tag types were statistically compared on day 14 as it was the last sampling point when all tag types were still viable.

The cell viability measurements (Figure 2) indicated an overall decrease for all treatments and the control. Two hours after tagging, 0.36 OD540 and stabilized at 0.12 OD540 throughout the remainder of the trial. The different tags types followed a similar pattern. PIT tagged individuals after hours measured 0.36 OD540 and stabilized at 0.12 OD540, while beaded individuals, after two hours, were 0.58 OD540 and stabilized at 0.10 OD540. Fingernail polished individuals after two hours was measured at 0.32 OD540 and stabilized at 0.11 OD540. The fingernail polish tag type was significantly different $(\mathrm{p}<0.05)$ from other tag types on day 14. There was not enough sea urchin coelomocyte left over to sample until day 28 due to mortality. Nitric oxide

\begin{tabular}{|l|c|c|c|}
\hline \multirow{2}{*}{ Tag Option } & \multicolumn{2}{|c|}{ Trial 1.1 } & \multirow{2}{*}{$\begin{array}{c}\text { Trial 1.2 } \\
\text { (Mortality) }\end{array}$} \\
\cline { 2 - 4 } Control & Mortality & Tag Loss & $20 \%$ \\
\hline Bead & $25 \%$ & & $90 \%$ \\
\hline PIT Tag & & $100 \%$ & $60 \%$ \\
\hline $\mathbf{2 0 ~} \mathbf{~ m m ~ I n d i v i d u a l s ~}$ & $22.5 \%$ & & \\
\hline $\mathbf{4 0} \mathbf{~ m m ~ I n d i v i d u a l s ~}$ & & $52.5 \%$ & $100 \%$ \\
\hline Nail Polish & $100 \%$ & & \\
\hline \multicolumn{2}{|r|}{ Table 1: Tag retention and survival in P. lividus. } \\
\hline
\end{tabular}




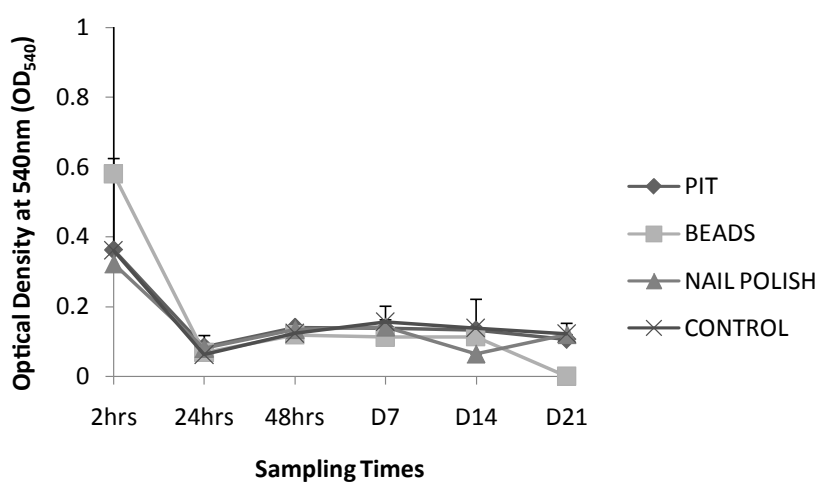

Figure 2: Cell viability, measured in optical density, for pooled $P$. lividus individuals tagged with different tagging options over a 28 day period.

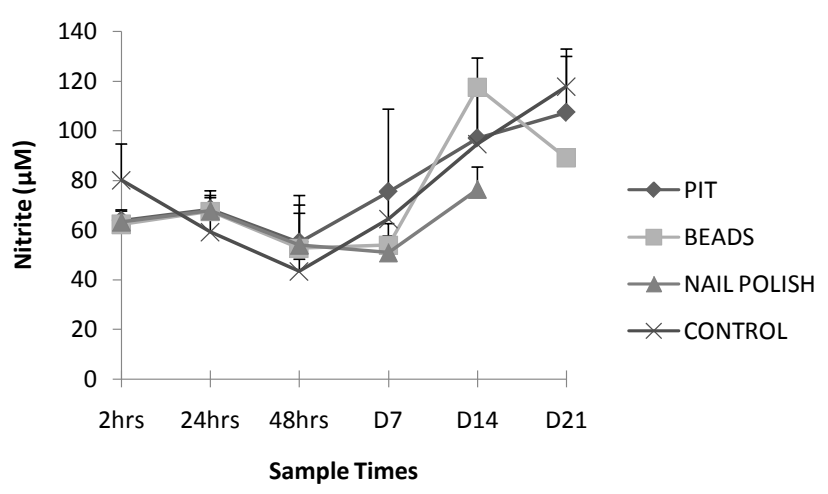

Figure 3: Nitric oxide levels for pooled $P$. lividus individuals tagged with different tagging options over a 28 day period.

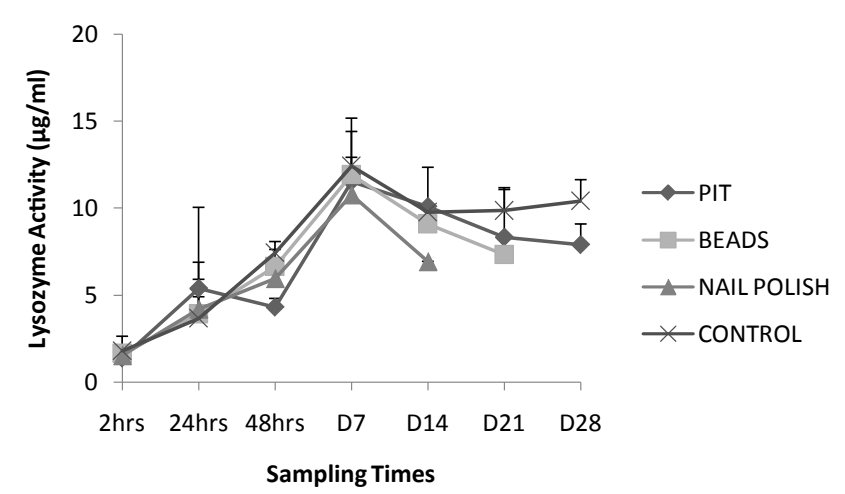

Figure 4: Lysozyme activity data pooled $P$. lividus individuals tagged with different tagging options over a 28 day period.

levels (Figure 3) showed an initial 48hr decrease after tagging followed by general increases in all tag types and controls until the end of the experiment. The controls at T2 measured $80.04 \mu \mathrm{M}$ which decreased to $43.3 \mu \mathrm{M} 237$ at $\mathrm{T} 48$ and then increased to $117.78 \mu \mathrm{M}$ on day 21 . The different tag types followed a similar pattern. PIT tagged individuals at T2 measured $63.8 \mu \mathrm{M}$ which decreased to $55.01 \mu \mathrm{M}$ at T48 and then increased to $107.28 \mu \mathrm{M}$ on day 21. Beaded individuals at T2 were 62.35 $\mu \mathrm{M}$ which decreased to $52.7 \mu \mathrm{M}$ at $\mathrm{T} 48$ and then increased to 107.28 $\mu \mathrm{M}$ at T21. Fingernail polished individuals at T2 were $63.26 \mu \mathrm{M}$ which decreased to $54 \mu \mathrm{M}$ at T48 and then increased until they died off on day
14. The bead tag type was significantly different $(\mathrm{p}<0.001)$ from other tag types on day 14. There was not enough sea urchin coelomocyte left over to sample until day 28 due to mortality. Lysozyme activity (Figure 4) showed a general increase in all tag types and the control until day 7. The controls at T2 measured $1.79 \mu \mathrm{g} / \mathrm{ml}$, peaked at 12.42 $\mu \mathrm{g} / \mathrm{ml}$ and measured $10.41 \mu \mathrm{g} / \mathrm{ml}$ at TDay28. The different tags types followed a similar pattern. PIT tagged individuals at T2 measured 1.37 $\mu \mathrm{g} / \mathrm{ml}$, peaked at $11.51 \mu \mathrm{g} / \mathrm{ml}$ and measured $7.89 \mu \mathrm{g} / \mathrm{ml}$ at TDay28, beaded individuals at T2 were $1.63 \mu \mathrm{g} / \mathrm{ml}$ peaked at $11.92 \mu \mathrm{g} / \mathrm{ml}$ and wasn't viable at TDay28, and fingernail polished individuals at T2 were $1.52 \mu \mathrm{g} / \mathrm{ml}$, peaked at $10.77 \mu \mathrm{g} / \mathrm{ml}$ and wasn't viable at TDay 28 . The fingernail polish tag type was significantly different $(\mathrm{p}<0.05)$ from other tag types on day 14 [36].

\section{Trial 3: Field detection of PIT tags}

In the field, individuals $(\mathrm{n}=44 ; 20 \pm 5 \mathrm{~mm}$ and $40 \pm 5 \mathrm{~mm}$ ) were monitored four times over a two month period (Table 2). Tag identification numbers were recorded in order to observe individual occurrences and tag feasibility. One week after releasing the PIT tagged individuals into the rock pool, $2.3 \%$ of individuals were recaptured and identified. However, 3 weeks after the animals were replaced, $13.6 \%$ of individuals were recaptured. $11.4 \%, 20.5 \%$, and $4.5 \%$ individuals were caught and recaptured on weeks 4,5 , and 6, respectively. Altogether 12 individuals (27\%) were identified and captured over the 6 week period [37,38].

\section{Discussion}

Previous studies using PIT tagged aquatic invertebrates claim that PIT tagging does not adversely affect survival [6,39-42]. Therefore, the higher mortality from this study could be due to sensitivity of P. lividus, condition of the individuals at the time of the experiment or the host response to the tags. Three tag types were used 271 in this study: glued craft beads, nail polish and PIT tags. The glued crafts beads could be viable for short term experiments that last less than two weeks and don't involve host response measurements. It was observed that the sea urchins dropped the spines with the beads, possibly as a defense mechanism. The fingernail polish resulted in $100 \%$ mortality. This was could be due to the fact that a) the epithelial layer with the fingernail polish became detached within $24 \mathrm{hrs}$ of application layer making the urchin susceptible to infection and b) some urchins were observed to have a swollen peristomal membrane possibly indicating the fingernail polish, when applied, covered the anus preventing waste expulsion (personal observation). The specific PIT tag used in this study was 4 $\mathrm{mm}$ smaller than tags used in previous studies [6,36-39]. In our initial tag retention trial, the mortality rate observed was lower in the smaller individuals than in the larger individuals possibly due to the life history and previous holding conditions of the urchins. The most successful marker in this study was the PIT tag with applications in denoting ownership and tracking individuals.

Trial 1 showed that survival in the smaller sized urchins with PIT tags was the same as in the control group. The poorer survival in the larger PIT tagged individuals may have been due to their previous life history in the hatchery. Upon dissection of PIT tagged individuals, it was observed that the tag was lodged in the membrane covering the inside of the test (personal observation). In a study by Parker and Ranken [39] on PIT tagging in Black Rockfish, it was suggested that the movement of tags could be the cause of observed mortalities. Christy [26] observed PIT tags lodged in the outer peritoneum of two frogs (Limnodynastesperonii). This may have contributed to the mortalities observed in PIT tagged urchins in this study as the PIT tag was inserted 


\begin{tabular}{|c|c|c|c|c|c|}
\hline \multicolumn{6}{|c|}{ Weeks post releasing to the field $(n=44)$} \\
\hline Individual PIT Codes & $\begin{array}{c}\text { Week } 1 \\
\text { Aug. } 232013\end{array}$ & $\begin{array}{c}\text { Week } 3 \\
\text { Sept. } 042013\end{array}$ & $\begin{array}{c}\text { Week } 4 \\
\text { Sept. } 122013\end{array}$ & $\begin{array}{c}\text { Week } 5 \\
\text { Sept. } 172013\end{array}$ & $\begin{array}{c}\text { Week } 6 \\
\text { Oct. } 212013\end{array}$ \\
\hline $\begin{array}{l}3458321 \\
(15.4 \mathrm{~g})\end{array}$ & $\checkmark$ & & & & \\
\hline $\begin{array}{l}3480739 \\
(41.2 \mathrm{~g})\end{array}$ & & $\checkmark$ & $\checkmark$ & $\checkmark$ & \\
\hline $\begin{array}{l}3440163 \\
(12.1 \mathrm{~g})\end{array}$ & & $\checkmark$ & & $\checkmark$ & \\
\hline $\begin{array}{l}3483893 \\
(6.6 \mathrm{~g})\end{array}$ & & $\checkmark$ & & $\checkmark$ & \\
\hline $\begin{array}{l}3474164 \\
(8.4 \mathrm{~g})\end{array}$ & & $\checkmark$ & $\checkmark$ & $\checkmark$ & \\
\hline $\begin{array}{l}3483706 \\
(38.6 \mathrm{~g})\end{array}$ & & $\checkmark$ & & $\checkmark$ & \\
\hline $\begin{array}{l}3475231 \\
(26.5 \mathrm{~g})\end{array}$ & & $\checkmark$ & $\checkmark$ & $\checkmark$ & \\
\hline $\begin{array}{l}3466602 \\
(25.8 \mathrm{~g})\end{array}$ & & & $\checkmark$ & $\checkmark$ & \\
\hline $\begin{array}{l}3467376 \\
(30.2 \mathrm{~g})\end{array}$ & & & & $\checkmark$ & \\
\hline $\begin{array}{l}3447800 \\
(12.6 \mathrm{~g})\end{array}$ & & & & $\checkmark$ & \\
\hline $\begin{array}{l}3476882 \\
(33.5 \mathrm{~g})\end{array}$ & & & & & $\checkmark$ \\
\hline $\begin{array}{l}3784860 \\
(10.4 \mathrm{~g})\end{array}$ & & & & & $\checkmark$ \\
\hline$\%$ of individuals recaptured & 2.3 & 13.6 & 11.4 & 20.5 & 4.5 \\
\hline
\end{tabular}

Table 2: Recapture rate for PIT tagged urchins in the rock pool over a 6 week period.

into the coelomic cavity where it could move around, conceivably causing internal damage. Additionally, upon the completion of the experiment, eight of the surviving PIT tagged animals were dissected in order to locate the PIT tag. It was observed that the tag was starting to be encased in the tissue lining of the test. This observation has not been reported before and warrants further investigation. Although individual tagging has been used for many years in different species (mainly vertebrates) [43], other studies using nPIT tags on aquatic invertebrates include prawns, Macrobrachiumrosenbergii [44], freshwater signal crawfish, Pacifastacusleniusculus [38], pot-bellied seahorses, Hippocampus abdominalis [41], green sea urchins, Strongylocentrotusdroebachiensis $[6,45]$, the kina sea urchin, Evechinuschloroticus, sea cucumbers, Holothuriawhitmaeiand Actinopygamiliaris [4], and freshwater pearl mussels, Margaritiferamargaritifera [46], easternlampmussels, Lampsilisradiataradiata [42] 305 with varying success as viable markers. Other studies using similar tagging techniques to this study, such as Agatsuma et al. [47] reported successful tagging of Strongylocentrotusnuduss pines with different colors of fingernail polish and covering the polish with a quick drying dental adhesive but only for trials lasting for shorter than three days. No studies to our knowledge have used craft beads glued to the spines.

There have been few studies on the effects of tagging on the host, especially in invertebrates [46]. This is the first study looking at host response to tagging in P. lividus using immune parameters as indicators of host response. Trial 1 was designed to assess tagging viability and mortality, while Trial 2 was designed to test immune parameters of the tagged host. All animals in Trial 2 showed host response, and higher mortality when compared to Trial 1 , including the controls, due to handling and sampling of the coelomic fluid via insertion of a syringe into the peristomal membrane. The overall decrease in cell viability within the treatment groups, as well as the controls, may be due to tag effects. With less viable cells, phagocytosis decreases as well; therefore decreasing capability of an immune response. Upon introduction of a stressor, the host will liberate oxygen and free radicals, such as nitric oxide which is a potent bactericidal [48-51]. Our nitric oxide (NO) measurements indicate that the sea urchin coelomocytes produced NO with increased production at $48 \mathrm{hrs}$; however, whether it was due to the tags or to the sampling is unclear and would need further verification. Lysozyme is an enzyme that can hydrolyse components of bacterial walls; therefore, aiding in immune defense and digestion [52]. Lysozyme results from this study indicate an increase in host response until day seven followed by a decrease in lysozyme activity in all treatments excluding the controls. Again, the initiation of the host response, whether it was due to the tags or to the sampling methodology, is unclear and would need further verification. Behavior studies should be developed to determine a less invasive ways of measuring stress and host response because the methodology used in this study challenged all individuals including the controls. Therefore, it is necessary to develop an alternative way of measuring host response (i.e. the activity of the podia and the configuration of the spines). In the capture, monitor, and release study, surviving tagged individuals from the tag retention experiment were ranched in natural rock pools on the west coast of Ireland. The recaptured urchins had retained their PIT tags for at least five months (laboratory and field) and were easily scanned with a portable universal microchip reader (RealTrace RT100) (standard in veterinary practices); however, there are two limitations 339 to using PIT tags in the field: 1) sea urchins preferably hide in the crevasses between rocks which limits accessibility and 2) the relatively short distance from which tags can be detected (also reported in Bubb et al. [38]). One way to address these limitations is to apply a technique suggested by Bubb et al. [38] and Roussel et al. [53], which calls for the use of a coil antenna or and 'open coil' antenna mounted on a pole to facilitate searching for tagged individuals in aquatic environments full of rocky crevasses. PIT tagging permits repeated non-destructive sampling of individuals. The claim that this technique has a theoretically indefinite life span, negligible tagging mortality, high 
Citation: Cipriano A, Burnell G, Culloty S, Long S (2014) Evaluation of 3 Tagging Methods in Marking Sea Urchin, Paracentrotuslividus, Populations under Both Laboratory and Field Conditions. J Aquac Res Development 5: 276 doi:10.4172/2155-9546.1000276

Page 6 of 7

tag retention, and no apparent long term effects on growth and survival of tagged individuals [38], needs further verification in $P$. lividus. The PIT tags used in this study was a useful mechanism for individual sea urchin identification in the laboratory and in the subsequent field study. Additionally, this method, provided tagged individuals are held in captivity for three months to test for tag retention, allows for a large number of animals to be marked and has the potential to address numerous questions relating to the behaviour, mobility, habitat use, brood stock management, and denotes ownership within the laboratory and in the field.

Fingernail polish was the least successful tagging technique and caused $100 \%$ mortality. The bead technique is a temporary tagging solution but is highly stressful when compared to the control and PIT tagged individuals. Urchins released into rock pools were detected up to 6 weeks after release indicating that the use of these smaller PIT tags are a viable option in sea urchin culture.

\section{Acknowledgement}

We would like to thank Luke Harman, Maria O'Mahoney, and Elaine Brennan for all their assistance in the laboratory and John Chamberlin.

\section{References}

1. Charles Y, Muki S, Thierry C, Shawn R (2010) Global Conference on Aquaculture.

2. Emery L, Wydoski RS (1987) Marking and tagging of aquatic animals: an indexed bibliography. US Dep Inter Fish Wildl Serv 57: 165

3. Freilich JE (1989) A Method for Tagging Individual Benthic Macroinvertebrates. J North Am Benthol Soc 8: 351-354.

4. Purcell SW, Agudo NS, Gossuin, H (2008) Poor retention of passive induced transponder (PIT) tags for mark-recapture studies on tropical sea cucumbers. SPC Beche Mer Inf Bull 28: 53-55.

5. Reisser J, Proietti M, Kinas P, Sazima, I (2008) Photographic identification of sea turtles: method of description and validation, with an estimation of tag loss. Endang Species Res 5: 73-82.

6. Hagen NT (1996) Tagging sea urchins: a new technique for individual identification. Aquaculture 139: 271-284.

7. Houghton JDR, Doyle TK, Davenport J, Hays GC (2006) Developing a simple, rapid method for identifying and monitoring jellyfish aggregations from the air. Mar Ecol Prog Ser 314: 159-170.

8. Turon X, Giribet G, Lopez S, Palacin C (1995) Growth and population structure of Paracentrotus lividus (Echinodermata: Echinoidea) in two contrasting habitats. Mar Ecol Prog Ser 122: 193-204.

9. Boudouresque CF, Verlaque $\mathrm{M}$ (2002) Biological pollution in the Mediterranean Sea: invasive versus introduced macrophytes. Mar Pollut Bull 44: 32-38.

10. Pais A, Chessa LA, Serra S, Ruiu A, Meloni G, Donno Y (2007) The impact of commercial and recreational harvesting for Paracentrotus lividus on shallow rocky reef sea urchin communities in North-western Sardinia, Italy. Estuar. Coast. Shelf Sci 73: 589-597.

11. FAO (2012) The State of World Fisheries and Aquaculture 2012.

12. Moore HB (1935) A comparison of the biology of Echinus esculentus in different habitats. Part II J Mar Biol Assoc United Kingdom New Ser 20: 109-128.

13. Sinclair AN (1959) Observations on the behaviour of sea urchins. Aust Mus Mag 13: 3-8.

14. Agatsuma Y (2001) Ecology of Hemicentrotus pulcherrimus, Pseodocentrotus depressus and Anthocidaris crassispina in southern Japan. Developments in Aquaculture and Fisheries Science Elsevier 32: 363-374.

15. Fuji AR (1963) On the growth of the sea urchin, Hemicentrotus pulcherrimus (A.Agassiz). Bull Jpn Soc Sci Fish 29: 118-126.

16. Ebert TA (1965) A Technique for the Individual Marking of Sea Urchins. Ecology 46: 193-194

17. Lees DC (1968) Tagging subtidal echinoderms.
18. Olsen M, Newton G (1979) A simple, rapid method for marking individual sea urchins. Calif. Fish Game 65: 58-62.

19. Ebert TA (1977) An experimental analysis of sea urchin dynamics and community interactions on a rock jetty. J Exp Mar Bio Ecol 27: 1-22.

20. Gage JD (1992) Natural growth bands and growth variability in the sea urchin Echinus esculentus: results from tetracycline tagging. Mar Biol 114: 607-616.

21. Kenner MC (1992) Population dynamics of the sea urchin Strongylocentrotus purpuratus in a Central California kelp forest: recruitment, mortality, growth and diet. Mar Biol 112: 107-118.

22. Ebert TA, Russell MP (1993) Growth and mortality of subtidal red sea urchins (Strongylocentrotus franciscanus) at San Nicolas Island, California, USA problems with models. Mar Biol 117: 79-89.

23. Prentice EF, Park DL, Sims CW (1984) A study to determine the biological feasibility of a new fish tagging system. Portland.

24. Prentice EF, Flagg TA, McCutcheon CS (1990) Feasibility of using implantable passive integrated transponder (PIT) tags in salmonids. Am Fish Soc Symp 7 317-322.

25. Hagen NT (1991) A new technique for the individual tagging of sea urchins.

26. Galimberti F, Sanvito S, Boitani L (2000) Marking of southern elephant seals with passive integrated transponders. Mar Mammal Sci 16: 500-504.

27. Gauthier Clerc M, Le Maho Y (2001) Beyond Bird Marking With Rings. Ardea 89: 221-230.

28. Godfrey JD, Bryant DM, Williams MJ (2003) Radio-telemetry increases freeliving energy costs in the endangered Takahe Porphyrio mantelli. Biol Conserv 114: 35-38.

29. Matranga V (Ed.) (2005) Echinodermata: Progress 440 in Molecular and Submolecular Biology.

30. Tafalla C, Gómez-León J, Novoa B, Figueras A (2003) Nitric oxide by carpet shell clam (Ruditapes decussatus) hemocytes. Development and Comparative Immunology 27: 197-205.

31. Cronin MA, Culloty SC, Mulcahy MF (2001) Lysozyme activity and protein concentration in the haemolymph of the flat oyster Ostrea edulis (L.). Fish Shellfish Immunol 11: 611-622.

32. Rogers LM, Hounsome TD, Cheeseman CL (2002) An evaluation of passive integrated transponders (PITs) as a means of permanently marking badgers (Meles meles). Mamm Rev 32: 63-65

33. Woods CMC, James PJ (2005) Evaluation of passive integrated transponder tags for individually identifying the sea urchin Evechinus chloroticus (Valenciennes). Aquac Res 36: 730-732.

34. Carballal MJ, Lopez C, Azevedo C, Villalba A (1997) Enzymes Involved in Defense Functions of Hemocytes of Mussel Mytilus galloprovincialis. J Invertebr Pathol 70: 96-105.

35. Shugar D (1952) The measurement of lysozyme activity and the ultra-viole inactivation of lysozyme. Biochem Biophys Acta, 8: 302-309.

36. Dutton PH, McDonald D, MacDonald DL (1994) Use of PIT tags to identify adult leatherback. Mar Turt Newsl 67: 13-14.

37. Christy MT (2006) The efficacy of using Passive Integrated Transponder (PIT) tags without anaesthetic in free-living frogs. Aust Zool 30: 139-142.

38. Bubb DH, Lucas MC, Thom TJ, Rycroft P (2002) The potential use of PIT telemetry for identifying and tracking crayfish in their natural environment Hydrobiologia 483: 225-230.

39. Parker SJ, Rankin PS (2003) Tag Location and Retention in Black Rockfish Feasibility of Using PIT Tags in a Wild Marine Species. North Am J Fish Manag 23: 993-996.

40. Wiles PR, Guan RZ (1993) Studies on a new method for permanently tagging crayfish with microchip implants. Freshwater Crayfish 9: 419-425.

41. Woods CMC (2005) Evaluation of VI-alpha and PIT-tagging of the seahorse Hippocampus abdominalis. Aquac Int 13: 175-186.

42. Kurth J, Loftin C, Zydlewski J, Rhymer J (2007) PIT tags increase effectiveness 
Citation: Cipriano A, Burnell G, Culloty S, Long S (2014) Evaluation of 3 Tagging Methods in Marking Sea Urchin, Paracentrotuslividus, Populations under Both Laboratory and Field Conditions. J Aquac Res Development 5: 276 doi:10.4172/2155-9546.1000276

43. Jenkins WE, Smith TIJ (1990) Use of 474 PIT tags to individually identify striped bass and red drum brood stocks.

44. Caceci T, Smith SA, Toth TE, Duncan RB, Walker SC (1999) Identification of individual prawns with implanted microchip transponders. Aquaculture 180: $41-51$

45. Duggan RE, Miller RJ (2001) External and internal tags for the green sea urchin. J Exp Mar Bio Ecol 258: 115-122.

46. Wilson CD, Arnott G, Reid N, Roberts D (2011) The pitfall with PIT tags: marking freshwater bivalves for translocation induces short-term behavioural costs. Anim Behav 81: 341-346.

47. Agatsuma YU, Nakata AK, Matsuyama KE (2000) Seasonal foraging activity of the sea urchin Strongylocentrotus nudus on coralline flats in Oshoro Bay in south-western Hokkaido, Japan. Fish Sci 66: 198-203.

48. Kumar V, Jindal SK, Ganguly NK (1995) Release of reactive oxygen and nitrogen intermediates from monocytes of patients with pulmonary tuberculosis Scand J Clin Lab Invest 55: 163.

49. Pacelli R, Wink DA, Cook JA, Krishna MC, De Graff W, et al. (1995) Nitric oxide potentiates hydrogen-peroxide induced killing of Escherichia coli. J Exp Med 182: 1469-1479.

50. Wheeler MA, Smith SD, García-Cardenã G, Nathan CF, Weiss RM, et al (1997) Bacterial infection induces nitric oxide synthase in human neutrophils. J Clin Invest 99: 110-116.

51. Fang FC (1997) Perspectives series: host/pathogen interactions. Mechanisms of nitric oxide-related antimicrobial activity. J Clin Invest 99: 2818-2825.

52. Cheng TC (1983) The role of lysozymes in molluscan inflammation. American Zoologist 23: 129-144.

53. Roussel JM, Haro A, Cunjak RA (2000) Field test of a new method for tracking small fishes in shallow rivers using passive integrated transponder (PIT) technology. Can J Fish Aquat Sci 57: 1326-1329. 